\title{
Age-Sex Structure of the Population and Demographic Processes in Environmentally Challenged Mining Region (on the example of Kemerovo region)
}

\author{
Timofey Leshukov ${ }^{1}$, Olga Brel $^{1^{*}}$, Anna Zaytseva ${ }^{1}$, Philipp Kaizer ${ }^{1}$, and Kirill Makarov ${ }^{1}$ \\ ${ }^{1}$ Kemerovo State University, Department of Geology and Geography, 650000, Kemerovo, Krasnaya \\ Street, 6, Russia
}

\begin{abstract}
The main goal of the article is to show the influence of the agesex structure of the population on the basic demographic processes in the Kemerovo region. During research the authors have established correlation links between the sex-age structure of the population and the main demographic indicators (birth and mortality rate, morbidity rate, migration and others) based on the analysis of official statistical data. The direct influence of internal and external factors on the age-sex structure of the population is revealed. Conclusions about the impact of demographic processes on the sex-age structure of the population of the Kemerovo region are drawn.
\end{abstract}

\section{Introduction}

The Kemerovo region is one of the most important industrial centers of Russia which is fairly attributed to the old industrial regions. The effectiveness and dynamics of the development of the region largely depend on its population: the number, growth rate, life expectancy, migration, etc. The demographic situation in the Kemerovo region, as well as the country in general, is characterized by a steady population decline. The Kemerovo region is not considered a depressive territory, but a number of features of the old industrial region are inherent in it (the dominance of the early industrial branches - coal-mining and metallurgy, the underdeveloped social infrastructure in a number of coal-mining villages of the region, a high proportion of people engaged in heavy physical labor, etc.). The social and economic development of the Kemerovo region is substantially determined by factors which are external to the region. They are defined by the overall dynamics of the socioeconomic situation in the country and the situation in the commodity markets of the basic sector of the region's economy - extraction and primary processing of raw materials [1].

Demographic processes which are formed from a large number of various components that affect them are typical for each region. These determinants can be usually divided into external and internal factors in their relation to the community of people. External or exogenous factors are caused by the impact of the environment on the people community, form-

* Corresponding author: brel_o_a@mail.ru 
ing certain demographic processes. Internal or endogenous factors are associated with internal processes occurring in the community itself.

As a rule, the endogenous factors influencing demographic system are laid in the human population itself and are described by probability of approach of a demographic event. For example, among senior-age people an increased mortality and morbidity from blood circularity system diseases and neoplasms are observed [2]. Proceeding from it in areas where the age-sex structure of the population will have a regressive form, one should expect a higher incidence of morbidity and mortality from these pathologies. Aging of the population should be expected in the old industrial regions. It'll naturally lead to a decrease in the demographic potential of the territory, which in turn will affect the decline in fertility, the increase in mortality and morbidity of cardiovascular system diseases and malignant neoplasms, and will also lead to an intensification of immigration processes in the region.

Internal factors defining the demographic development of the municipalities of the Kemerovo region are the differences in the age and sex structure of their population. Territorial differences in the number of people assigned to different age groups lead to spatial differentiation of demographic events that are pre-characterized for a particular age. The probability of this event increases with the approach to the average age of its onset or decreases with the distance from it (for example, death from a heart attack or stroke is characteristic of senior-age people). These events can be, f. ex.: the average age of death from blood circulatory system diseases and neoplasms, the average age of the mother at childbirth, the age at which the greatest number of certain types of newly diagnosed diseases are observed, the age groups of migrants [3].

Age-sex structure has a serious impact on the level and causes of mortality. The older population will have a higher overall mortality rate. It is also known that the male population, aged 15 and over, has a higher rate of age-related mortality, in relation to the similar rate of female mortality. The main causes that lead to the death of the young population are the external causes of death associated with accidents, murders, car accidents, etc. [4].

\section{Materials and Methods}

The article deals with the analysis of the main demographic processes (fertility, mortality, migration). Based on the results of the analysis, their relationship to the age and sex structure of the population of the municipal districts and urban districts of the Kemerovo region. According to the results of the analysis, the authors established their relationship with the age-sex structure of the population of the municipal districts and urban territories of the Kemerovo region. All the data for analysis are taken from the official statistical sources. The processing of statistical data and correlation links were made by using the Spearman correlation coefficient. A check of statistical significance was carried out by the Student's criterion at a level not less than 0.05 with the use of the program "Statistic 10.1".

\section{Results and Discussion}

Distribution of age mortality rates in all countries confirms the increase in probability of approach of a demographic event - death with age [5]. At a high level of life the intensity of increase of this probability decreases that is provided with timely diagnosis of diseases and effective protocols of treatment. As a rule the quality of environment and specialization on "dirty" braches in old industrial regions create conditions for the earlier development of certain types of pathologies, including cardiovascular and pulmonary disease. The study found correlation between the age-sex structure of the population and the overall mortality rate (Tab.1). The strongest link is noted between the total mortality and the number of peo- 
ple over 50-years old. This correlation confirms the fact of an increase in the mortality rate in those regions where more adult population lives. For all the proposed parameters, a fairly high correlation is observed at a high statistical significance.

In the areas where there are more people over the age of 50, the total mortality rate will exceed the average regional rate. In this case the improvement of the demographic situation can be achieved by the prevention and timely diagnosis and also modern treatment of quasiendogenous and endogenous diseases. These measures will increase the life expectancy of the population and avoid depopulation.

Table 1. Correlation between age and sex structure and total mortality rate.

\begin{tabular}{|c|c|c|c|}
\hline $\begin{array}{l}\text { Index } \\
\text { (2015) }\end{array}$ & $\begin{array}{c}\text { Spearman's } \\
\text { rank correlation } \\
\text { coefficient }\end{array}$ & $t$-test & p-value \\
\hline Population over 70 years old, $\%$ & \multirow{2}{*}{0.518462} & \multirow{2}{*}{3.429847} & \multirow{2}{*}{0.001683} \\
\hline Total mortality rate, $\%$ & & & \\
\hline Population over 60 years old, $\%$ & \multirow{2}{*}{0.634967} & \multirow{2}{*}{4.649492} & \multirow{2}{*}{0.000055} \\
\hline Total mortality rate, $\% o$ & & & \\
\hline Population over 50 years old, $\%$ & \multirow{2}{*}{0.716000} & \multirow{2}{*}{5.801907} & \multirow{2}{*}{0.000002} \\
\hline Total mortality rate, $\%$ & & & \\
\hline Men population over 50 years old, $\%$ & \multirow{2}{*}{0.512040} & \multirow{2}{*}{3.372141} & \multirow{2}{*}{0.001964} \\
\hline Total mortality rate, $\%$ & & & \\
\hline Men population over 60 years old, $\%$ & \multirow{2}{*}{0.571822} & \multirow{2}{*}{3.942955} & \multirow{2}{*}{0.000411} \\
\hline Total mortality rate, $\%$ & & & \\
\hline $\begin{array}{l}\text { Women population over } 50 \text { years old, } \\
\%\end{array}$ & \multirow{2}{*}{0.666922} & \multirow[t]{2}{*}{5.063129} & \multirow[t]{2}{*}{0.000017} \\
\hline Total mortality rate, $\%$ & & & \\
\hline $\begin{array}{l}\text { Women population over } 60 \text { years old, } \\
\%\end{array}$ & \multirow[t]{2}{*}{0.548429} & \multirow[t]{2}{*}{3.710111} & \multirow[t]{2}{*}{0.000785} \\
\hline Total mortality rate, $\%$ o & & & \\
\hline $\begin{array}{l}\text { Women population over } 70 \text { years old, } \\
\%\end{array}$ & \multirow[t]{2}{*}{0.570905} & \multirow[t]{2}{*}{3.933567} & \multirow[t]{2}{*}{0.000422} \\
\hline Total mortality rate, $\%$ & & & \\
\hline
\end{tabular}

The most unfavorable situation is observed in the Tyazhinsky and Izhmorsky municipal districts, where from $38 \%$ to $40 \%$ of the population are over 50 years old. A decline in fertility caused by the output of a large part of the population from reproductive age will also be noted in these areas. It is also worth noting that in these areas there should be an increased incidence of morbidity and mortality from the circulatory system diseases and neoplasms, which requires appropriate measures from health facilities. The most favorable situation is observed in Kemerovo and Taiga urban districts, Mariinsky and Promyshlenniy municipal districts.

The age-sex structure also affects mortality from certain causes, as some pathologies develop significantly more often in older ages, which was found earlier and confirmed in this study (Tab. 2).

Correlation link is found between the number of deaths from tumors and the amount of people over 70 years old. The strongest correlation links were found between the proportion of people with mortality from the digestive system diseases and the proportion of women over 50-60 years of age.

Also a medium strength correlation with mortality from tumors was found among women. It should be noted that the absence of correlations with pathologies most often developing in older ages among men (oncopathology, circulatory system diseases) does not indicate the absence of these diseases, but it indicates higher risks of dying from external causes (injuries, alcohol poisoning, murder, suicide, car accidents) at earlier ages (correlation coefficient $0.42(\mathrm{p}<0.05))$. It's commonly known that age-sex structure has a significant effect 
on fertility and is associated with the biological abilities of the body to perform its reproductive function at early ages, and the extinction of this function with age. It is worth noting that the birth of a child in modern society has become not only a biologically determined fact, but also socially and economically determined event. It is confirmed by a decrease in the birth rate in the age groups of 18-24 and an increase in fertility in the ages of 25 to 29 years.

Table 2. Correlation links between mortality rate for a specified diseases and age-sex structure of municipalities' population.

\begin{tabular}{|c|c|c|c|}
\hline The mortality rate for & $\begin{array}{c}\text { Spearman's rank } \\
\text { correlation coef- } \\
\text { ficient }\end{array}$ & $t$-test & p-value \\
\hline circulatory system diseases per 100000 people & \multirow{2}{*}{0.374179} & \multirow{2}{*}{2.282482} & \multirow{2}{*}{0.029250} \\
\hline Population over 50 years old, $\%$ & & & \\
\hline neoplasms per 100000 people & \multirow{2}{*}{0.590114} & \multirow{2}{*}{4.134900} & \multirow{2}{*}{0.000239} \\
\hline Population over 70 years old, $\%$ & & & \\
\hline neoplasms per 100000 people & \multirow{2}{*}{0.505615} & \multirow{2}{*}{3.315170} & \multirow{2}{*}{0.002285} \\
\hline Population over 60 years old, $\%$ & & & \\
\hline neoplasms per 100000 people & \multirow{2}{*}{0.439147} & \multirow{2}{*}{2.765084} & \multirow{2}{*}{0.009367} \\
\hline Population over 50 years old, $\%$ & & & \\
\hline neoplasms per 100000 people & \multirow{2}{*}{0.589808} & \multirow{2}{*}{4.131616} & \multirow{2}{*}{0.000242} \\
\hline Women population over 50 years old, $\%$ & & & \\
\hline neoplasms per 100000 people & \multirow{2}{*}{0.536634} & \multirow{2}{*}{3.597540} & \multirow{2}{*}{0.001069} \\
\hline Women population over 60 years old, $\%$ & & & \\
\hline neoplasms per 100000 people & \multirow{2}{*}{0.557720} & \multirow{2}{*}{3.801002} & \multirow{2}{*}{0.000610} \\
\hline Women population over 70 years old, $\%$ & & & \\
\hline neoplasms per 100000 people & \multirow{2}{*}{0.353400} & \multirow{2}{*}{2.137027} & \multirow[b]{2}{*}{0.040338} \\
\hline Men population over 40 years old, $\%$ & & & \\
\hline neoplasms per 100000 people & \multirow{2}{*}{0.416043} & \multirow{2}{*}{2.588119} & \multirow{2}{*}{0.014394} \\
\hline Men population over 50 years old, $\%$ & & & \\
\hline respiratory diseases per 100000 people & \multirow{2}{*}{0.402903} & 2490228 & 0018140 \\
\hline Population over 60 years old, $\%$ & & 2.490228 & \\
\hline respiratory diseases per 100000 people & 0464629 & 2968183 & 0005633 \\
\hline Population over 50 years old, $\%$ & 0.464629 & 2.908183 & 0.005633 \\
\hline respiratory diseases per 100000 people & 0412987 & 2565184 & 0015203 \\
\hline Men population over 50 years old, $\%$ & $0.41298 /$ & 2.565184 & 203 \\
\hline respiratory diseases per 100000 people & 041 & 521 & 473 \\
\hline Women population over 50 years old, $\%$ & 1 & 2.3 & 0. \\
\hline digestive system diseases per 100000 people & & & \\
\hline Population over 70 years old, $\%$ & & 3.5 & 073 \\
\hline digestive system diseases per 100000 people & & & \\
\hline Population over 60 years old, $\%$ & & 3. & 432 \\
\hline digestive system diseases per 100000 people & 0.44953 & 2.846837 & 0.007648 \\
\hline Population over 50 years old, $\%$ & $0.44953 z_{2}$ & 2.846837 & $0.00 / 648$ \\
\hline digestive system diseases per 100000 people & & & \\
\hline Women population over 50 years old, \% & 0.600199 & 4.244836 & $0.0001 / 5$ \\
\hline digestive system diseases per 100000 people & 0617923 & 4445857 & 0000090 \\
\hline Women population over 60 years old, $\%$ & $0.01 / 923$ & $4.44585 /$ & \\
\hline digestive system diseases per 100000 people & & & \\
\hline Women population over 70 years old, \% & 0.520131 & 3.444977 & 0.001616 \\
\hline
\end{tabular}

Migration processes can be used as indicators of the aggregate competitive advantages of the regions. Migration can signal the adverse social, economic and environmental conditions of residence. Immigration processes are indicators of the competitive advantage of a 
single administrative education. Migration data is one of the problem areas of population statistics that is not correctly and systematically maintained. In 2015, a positive migration balance was observed only in the Kemerovo, Novokuznetsk and Berezovsky urban districts. From 2009 to 2015 almost all municipalities, except for Kemerovo, Novokuznetsk, Yurga urban districts and Kemerovo municipal district, showed a negative balance. The Yurga urban district showed a high intensity of migration flows due to the location of the military unit there. This territory can't be regarded as having competitive advantages. The remaining municipalities that have a positive migration balance are permanent centers of attraction of the population due to a higher quality of life. Those municipalities in which industrial monocities such as Belovo, Kiselevsk, Prokopyevsk, are located, are losing their population the most intensively. The age-sex structure of the population influences the migration activity of the population of the municipalities, that is confirmed by the statistically significant correlation $(\mathrm{p}<0.05)$ (Tab. 3).

Table 3. Correlation between age-sex structure of the population and amount of people emigrated from the municipalities

\begin{tabular}{|c|c|c|c|}
\hline Index & $\begin{array}{c}\text { Spearman's rank } \\
\text { correlation coefficient }\end{array}$ & $t$-test & p-value \\
\hline Emigration rate, \%o & \multirow{2}{*}{-0.389458} & \multirow{2}{*}{-2.39196} & \multirow{2}{*}{0.022804} \\
\hline Population aged $18-59$ years, $\%$ & & & \\
\hline Emigration rate, $\%$ & \multirow{2}{*}{-0.470130} & \multirow{2}{*}{-3.01322} & \multirow{2}{*}{0.005022} \\
\hline Population aged $25-59$ years, $\%$ & & & \\
\hline Emigration rate, \%o & \multirow[b]{2}{*}{-0.551413} & \multirow{2}{*}{-3.73908} & \multirow[b]{2}{*}{0.000725} \\
\hline Population aged $18-44$ years, $\%$ & & & \\
\hline Emigration rate, \%o & \multirow{2}{*}{-0.639114} & \multirow{2}{*}{-4.70071} & \multirow{2}{*}{0.000047} \\
\hline Population aged $25-44$ years, $\%$ & & & \\
\hline Emigration rate, $\%$ & \multirow[b]{2}{*}{-0.616099} & \multirow[b]{2}{*}{-3.12872} & \multirow[b]{2}{*}{0.006478} \\
\hline $\begin{array}{c}\text { Population of municipalities aged } \\
18-44 \text { years, } \%\end{array}$ & & & \\
\hline Emigration rate, $\%$ o & \multirow[b]{2}{*}{-0.717234} & \multirow[b]{2}{*}{-4.11711} & \multirow[b]{2}{*}{0.000807} \\
\hline $\begin{array}{l}\text { Population of municipalities aged } \\
25-44 \text { years, } \%\end{array}$ & & & \\
\hline
\end{tabular}

The greatest correlation link was found in the 25-44 age group as for the whole population of the Kemerovo region, as separately for the municipalities. The statistical links confirm the connection between the migration activity and working age groups. This circumstance should be taken into account when creating a program for the demographic development of the territory. It is also worth noting that the age and sex structure has a great influence on the prevalence of certain diseases, the frequency of their occurrence, and overall the incidence of the population. During the study, correlations were found between the agesex structure of the population and the frequency of oncological diseases (Tab. 4).

The revealed patterns of demographic processes occurring on the territory of the Kemerovo region, on the whole, correspond to all-Russian trends. However, regional specifics are also noted, due to both internal causes inherent in this region, and external factors (the level of socio-economic development, the state of the environment, etc.). The influence of external factors affects the lower life expectancy of the population of the Kemerovo region compared with the average Russian and world rates. For reducing the significance of external and internal factors that directly affect the age-sex structure of the population, a multilateral system of measures for stabilization the demographic situation in the Kemerovo region is needed. So, modernization and ecologization of the mining industry, ferrous and nonferrous metallurgy will improve the atmosphere condition, soil cover and surface water, which in turn will contribute to reducing mortality, increasing fertility, decline the level of newly diagnosed diseases among the population of the old industrial region [6]. 
Table 4. Correlation between age-sex structure of population and the level of newly diagnosed morbidity with various nosologies

\begin{tabular}{|c|c|c|c|}
\hline Rate of newly diagnosed morbidity of & $\begin{array}{c}\text { Spearman's rank } \\
\text { correlation coefficient }\end{array}$ & $t$-test & p-value \\
\hline All types of neoplasms per 100000 people & \multirow{2}{*}{0.505271} & \multirow{2}{*}{3.312139} & \multirow{2}{*}{0.002304} \\
\hline Population over 70 years old, $\%$ & & & \\
\hline All types of neoplasms per 100000 people & \multirow{2}{*}{0.394041} & \multirow{2}{*}{2.425255} & \multirow{2}{*}{0.021118} \\
\hline Population over 60 years old, $\%$ & & & \\
\hline All types of neoplasms per 100000 people & \multirow{2}{*}{0.466463} & \multirow{2}{*}{2.983145} & \multirow{2}{*}{0.005423} \\
\hline Women population over 50 years old, $\%$ & & & \\
\hline All types of neoplasms per 100000 people & \multirow{2}{*}{0.477158} & \multirow{2}{*}{3.071416} & \multirow{2}{*}{0.004325} \\
\hline Women population over 60 years old, $\%$ & & & \\
\hline All types of neoplasms per 100000 people & \multirow{2}{*}{0.508021} & \multirow{2}{*}{3.336415} & \multirow{2}{*}{0.002160} \\
\hline Women population over 70 years old, $\%$ & & & \\
\hline All types of pathologies per 1000 people & \multirow{2}{*}{-0.353400} & \multirow{2}{*}{-2.13703} & \multirow{2}{*}{0.040338} \\
\hline Men population over 40 years old, $\%$ & & & \\
\hline All types of pathologies per 1000 people & \multirow{2}{*}{-0.443545} & \multirow{2}{*}{-2.79951} & \multirow{2}{*}{0.008603} \\
\hline Men population over 50 years old, $\%$ & & & \\
\hline $\begin{array}{l}\text { Neoplasms of respiratory system per } 100 \\
000 \text { people }\end{array}$ & \multirow[t]{2}{*}{0.383346} & \multirow[t]{2}{*}{2.347901} & \multirow[t]{2}{*}{0.025225} \\
\hline Population over 50 years old, $\%$ & & & \\
\hline $\begin{array}{l}\text { Neoplasms of respiratory system per } 100 \\
000 \text { people }\end{array}$ & \multirow[t]{2}{*}{0.446600} & \multirow[t]{2}{*}{2.823582} & \multirow[t]{2}{*}{0.008104} \\
\hline Men population over 50 years old, $\%$ & & & \\
\hline $\begin{array}{l}\text { Neoplasms of respiratory system per } 100 \\
000 \text { people }\end{array}$ & \multirow[t]{2}{*}{0.361956} & \multirow[t]{2}{*}{2.196461} & \multirow[t]{2}{*}{0.035420} \\
\hline Men population over 60 years old, $\%$ & & & \\
\hline
\end{tabular}

According to Tab. 4, high rates of newly diagnosed morbidity of all localizations neoplasms are observed in groups in which there is a higher proportion of people older than 60-70 years. There is also an increase in the development of oncopathology in groups that have a high proportion of the female population older than 50-70 years. Such a pattern among men was not found. However, this may be due to the high men's mortality in earlier ages.

\section{Conclusions}

The results of the research indicate the necessity of creating a program for the region's development, taking into account the age-sex structure of the population. The necessity of prevention organization and early cardiovascular system diseases diagnosis and neoplasms is caused by a high proportion of people older than 50-70 years [7]. The development of social infrastructure objects, including the system of preschool and school institutions, is necessary because of a large proportion of 20-29 years people. The probability of childbearing is increase in this age group. A possible solution to the problem will be the development of a program for reducing male mortality, since the average life expectancy of men is 62-64 years (depending on the type of settlement). This indicator is $5.5 \%$ lower than on average in Russia. This program should contain activities aimed at reducing mortality from external causes, first of all by improving working conditions in mining enterprises. The problems related to the state of the environment remain unaccounted for. These problems are also relevant for mining enterprises and old industrial regions as a whole. For solutions these problems it's necessary to improve the ecological policy of the Kemerovo region by adopting appropriate laws. The development and implementation of a program of integrated 
measures within the framework of environmental and demographic policy will be the key to development of an innovative and post-industrial economy in the Kemerovo region.

\section{References}

1. F. Agafonov, A. Genin, O. Kalinina, O. Brel, O. Zhironkina, E3S Web of Conf., 15, 04011 (2017)

2. V. Aboyans, J. Abrahan, T. Adair, R. Aggarwal, S.Y. Ahn, M. AlMazroa, M. Alvarado, H. Anderson, L. Anderson, Global and regional mortality from 235 causes of death for 20 age groups in 1990 and 2010: A systematic analysis for the Global Burden of Disease Study 2010, 380, 2095-2128 (2012)

3. J. Hobcraft, J. Menken, S. Preston, Cohort analysis in social research: Beyond the identification problem (Springer-Verlag, New York, 1985)

4. H. Wang, L. Dwyer-Lindgren, K.T. Lofgren, J.K. Rajaratnam, J.R. Marcus, A. LevinRector, C.E. Levitz, A.D. Lopez, Christopher J. L. Murray, Age-specific and sexspecific mortality in 187 countries, 1970-2010: a systematic analysis for the Global Burden of Disease Study 2010, 380, 2071-2094 (2012)

5. C.J. Murray, A.D. Lopez, Global mortality, disability, and the contribution of risk factors: Global Burden of Disease Study, 349, 1436-1442 (1997)

6. J.A. Salomon, H. Wang, M.K. Freeman, T. Vos, A. Flaxman, A.D. Lopez, C.J. Murray, Healthy life expectancy for 187 countries, 1990-2010: a systematic analysis for the Global Burden Disease Study 2010, 380, 2144-2162 (2012)

7. Yu. Lesin, T. Leshukov, IOP Conf. Ser.: Mater. Sci. Eng., 142: 1, 012124 (2016) 
